[Agr. Biol. Chem., Vol. 32, No. 8, p. 956 962, 1968]

\title{
Production of Nucleic Acid-Related Substances by Fermentative Processes
}

\section{Part XVI. Accumulation of 5'-Inosinic Acid and 5'-Uridylic Acid by Brevibacterium insectiphilium}

\author{
By Takashi Nara, Isao Kawamoto, Masanaru Misawa \\ and Shukuo Kinoshita \\ Tokyo Research Laboratory, Kyowa Hakko Kogyo Co., Machida City, Tokyo \\ Received January 6, 1968
}

\begin{abstract}
Brevibacterium insectiphilium KY 3446 (Steinhous, Breed AHU 140I) was found to accumulate IMP from hypoxanthine and UMP from uracil, respectively. This strain is thus considered to present the fourth example in salvage-type fermentation, in addition to Micrococcus sjdonensis, Arthrobacter citreus and Brevibacterium ammoniagenes reported previously.

IMP from adenine and UMP from cytosine were also produced by KY 3446 , respectively. Further, the addition of inosine and adenosine instead of the bases also caused IMP accumulation.

This strain grew well on sucrose medium, and produced IMP and UMP in higher yields on sucrose than on glucose medium.

Excessive amounts of $\mathrm{Mn}^{2+}$ stimulated growth, but markedly inhibited IMP production. The optimal concentration of $\mathrm{Mn}^{2+}$ for IMP accumulation induced morphogenetic alterations from normal and small to abnormal and large cells.
\end{abstract}

The fermentative production of $5^{\prime}$-inosinic acid (IMP) was made possible either via $d e$ novo synthesis by adenine auxotrophs or via salvage synthesis by pertinent microorganisms. The de novo production is represented, for example, by IMP fermentations with adenineless mutants of Corynebacterium glutamicum ${ }^{1,21}$ and Brevibacterium ammoniagenes. ${ }^{31}$ On the other hand, IMP production from hypoxanthine by Micrococcus sodonensis, ${ }^{41}$ Arthrobacter citreus" and

1) K. Nakayama, T. Suzuki, Z. Sato and S. Kinoshita, J. Gen. Appl. Microbiol., 10, 133 (1964).

2) A. L. Demain, M. Jackson, R. A. Vitali, D. Hendlin and T. A. Jacb, Appl. Microbiol., 13, 757 (1965).

3) T. Nara, M. Misawa and S. Kinoshita, Agr. Biol. Chem., 31, 1351 (1967).

4) T. Nara, M. Misawa, T. Komuro and S. Kinoshita, Amino Acid and Nucleic Acid, No. 15, 19 (1967); Agr. Biol. Chem., 31, 1224 (1967).
$B r$. ammoniagenes $^{51}$ was recently reported as the salvage type of fermentation.

In further attempts to search for microorganisms capable of accumulating IMP, Brevibacterium insectiphilium was found, in addition to the foregoing three organisms, to accumulate IMP from either hypoxanthine or adenine. It was further noted that the culture was able to produce $5^{\prime}$-uridylic acid (UMP) from either uracil or cytosine.

The work reported here is to indentify IMP and UMP produced and to investigate cultural conditions in these fermentations with $B r$. insectiphilium.

5) T. Nara, M. Misawa and S. Kinoshita, Presented at Symposium on Amino Acid and Nucleic Acid, Sendai, October 3, 1967, Agr. Biol. Chem., in press (1968). 


\section{EXPERIMENTAL}

Microorganism used. Brevibacterium insectiphilium KY 3446 (Steinhous) Breed AHU 1401. This microorganism was gifted by courtesy of the Hokkaido University.

Fermentation techniques. This bacterial culture was maintained on a stock slant consisting of peptone $1 \%$, yeast extract $1 \%, \mathrm{NaCl} 0.25 \%$ and agar $2 \%$. A loopful of the culture was transferred to $20 \mathrm{ml}$ of a seed medium containing glucose $2 \%$, peptone $1 \%$, yeast extract $1 \%$ and $\mathrm{NaCl} 0.25 \%$ ( $\mathrm{pH} 7.3$ ). The medium in a $250 \mathrm{ml}$ Erlenmeyer flask was incubated for $24 \mathrm{hr}$ and $2 \mathrm{ml}$ of the seed culture were transferred to $20 \mathrm{ml}$ of fermentation medium in a $250 \mathrm{ml}$ Erlenmeyer flask. The basal composition of the fermentation medium is: glucose $10 \%, \mathrm{KH}_{2} \mathrm{PO}_{4} 1 \%$, $\mathrm{K}_{2} \mathrm{HPO}_{4} 1 \%, \mathrm{MgSO}_{4} \cdot 7 \mathrm{H}_{2} \mathrm{O} 1 \%$, urea $0.6 \%$ (autoclaved separately), $\mathrm{CaCl}_{2} \cdot 2 \mathrm{H}_{2} \mathrm{O} 0.01 \%$, yeast extract $1 \%$ and biotin $30 \mu \mathrm{g}$ per liter. Its $\mathrm{pH}$ was adjusted to 8.2 with $5 \mathrm{~N}-\mathrm{NaOH}$ before autoclaving. All incubations were run at $30^{\circ} \mathrm{C}$ on a rotary shaker operated at $220 \mathrm{rpm}$ and $5 \mathrm{~cm}$ diameter in a circle. All experiments were conducted in duplicate and the figures reported here are the averages of the values from two flasks.

Analytical methods. The quantity of IMP, hypoxanthine, UMP or uracil was determined by the paper chromatographic method with a solvent system consisting of isobutyric acid, $1 \mathrm{~N}$-ammonia and acetic acid $(10: 5: 1) .^{4)}$ The measurement of bacterial growth was made by the method previously described, ${ }^{11}$ Glucose was analyzed by the colorimentric method of Somogyi.61

\section{RESULTS}

IMP production from hypoxanthine or adenine

In the course of the investigation on microbial nucleotide accumulation, Brevibacterium insectiphilium KY 3446 was found to accumulate a IMP-like substance in the medium containing hypoxanthine as a precursor. Its UV absorption spectra and $R f$ values of paper chromatogram in various solvent systems ${ }^{11}$ were in good accord with those of an authentic IMP. The UV spectra of IMP extracted from the spot on paperchromatogram of KY 3446. culture broth are shown in Fig. 1. The above aqueous extracts of IMP were subjected to the action

6) M. Somogyi, J. Biol. Chem., 160, 61 (1945).

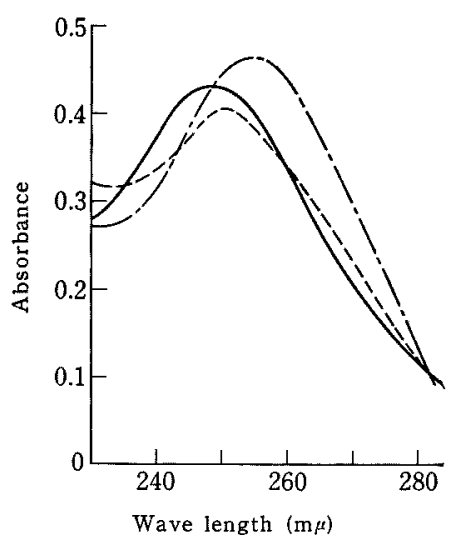

FIG. 1. UV Absorption Spectra of IMP Produced by KY. 3446 .

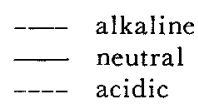

of $5^{\prime}$-nucleotidase to liberate inosine and to determine the molecular ratio of ribose, hypoxanthine and phosphorus. All the results accorded with those reported previously. ${ }^{3 !}$

It was consequently confirmed that $\mathrm{Br}$. insectiphilium KY 3446 accumulated IMP in the medium containing hypoxanthine as a precursor.

From the finding that IMP was not accumulated without hypoxanthine as a precursor, it seemed probable that IMP production by $\mathrm{KY}$ 3446 would proceed via salvage pathway, not via de novo pathway. Therefore it was examined whether the addition of other purine or pyrimidine bases to media might cause the accumulation of nucleotides corresponding to individual bases. As shown in Table I, the addition of adenine to medium was found to bring about IMP accumulation and the quantity was nearly as much as that accumulated from hypoxanthine. However, nucleotide accumulation did not occur when guanine or xanthine was added. It was also found that IMP was formed from inosine or adenosine, nucleoside corresponding to hypoxanthine or adenine. In the case, hypoxanthine was formed in both culture broths. 
TABLE I. PRODUCTS FROM BASES AND NUCleosides

$\begin{array}{ccccc}\text { Fermentation medium plus } & \begin{array}{c}\text { Addition time } \\ \text { (day) }\end{array} & \mathrm{pH} & \begin{array}{c}\text { Dried cell weight } \\ (\mathrm{mg} / \mathrm{ml})\end{array} & \begin{array}{c}\text { Accumulated product } \\ \text { (mg/ml) }\end{array} \\ \text { Adenine } & 0 & 8.0 & 8.3 & \text { IMP } 2.33 ; \text { hypoxanthine } \\ & 3 & 8.0 & 6.2 & \text { 1.88; hypoxanthine } \\ \text { Hypoxanthine } & 0 & 6.0 & 8.3 & \text { IMP } 2.08 \\ \text { Guanine } & 3 & 6.3 & 7.7 & \\ \text { Xanthine } & 3 & 6.8 & 8.6 & \\ \text { Cytosine } & 3 & 6.4 & 7.9 & \text { UMP 1.28; uracil } \\ \text { Uracil } & 3 & 6.2 & 7.6 & \text { UMP 1.46 } \\ \text { Orotic acid } & 3 & 6.0 & 7.1 & \\ \text { Thymine } & 3 & 7.2 & 11.8 & \\ \text { Adenosine } & 3 & 6.6 & 7.6 & \text { IMP 2.65; hypoxanthine } \\ \text { Inosine } & 3 & 6.0 & 5.8 & \text { IMP 2.44; hypoxanthine }\end{array}$

Medium; glucose $10 \%, \mathrm{~K}_{2} \mathrm{HPO}_{4} 1 \%, \mathrm{KH}_{2} \mathrm{PO}_{4} 1 \%$, yeast extract $1 \%, \mathrm{MgSO}_{4} \cdot 7 \mathrm{H}_{2} \mathrm{O} 1 \%, \mathrm{CaCl}_{2} \cdot 2 \mathrm{H}_{2} \mathrm{O}$ $0.01 \%$, urea (autoclaved separately) $0.6 \%$, biotin $30 \mu \mathrm{g} /$ liter. The mixture was adjusted to $\mathrm{pH} 8.3 \mathrm{before}$ autoclaving. Base (adenine, hypoxanthine, guanine, xanthine, cytosine, orotic acid, thymine and uracil) $0.3 \%$ and nucleoside (adenosine and inosine) $0.5 \%$, each was added. ( $\%$ as final concentration) Analyses were made for 5 day culture beer.

As shown in Table I, the time of base addition seemed not to affect the quantity of product significantly.

\section{UMP production from uracil or cytosine}

The products accumulated from pyrimidine bases (cytosine, orotic acid, thymine and uracil) are also shown in Table I. Both uracil and cytosine among those were noted to cause UMP accumulation, with the simultaneous formation of uracil in the case of cytosine.

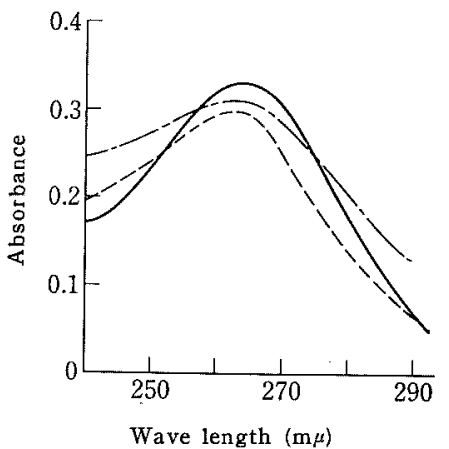

FIG. 2. UV Absorption Spectra of UMP Produced by KY. 3446 .
The UV absorption spectra of UMP produced from uracil are shown in Fig. 2. The preparation used was an aqueous extract of UMP from the spot on paperchromatogram of the broth. The UV spectra and $R f$ values in various solvents ${ }^{11}$ were in good accord with those of an authentic UMP. 5'-Phosphate ester was confirmed on paperchromatogram by a chemical method." UMP produced from cytosine was also characterized likewise by the above methods. It was thus verified that $B r$. insectiphilium was also able to produce UMP from either uracil or cytosine.

\section{Effect of manganese on IMP production}

As described previously, IMP production by Micrococcus sodonensis ${ }^{4}$ and Arthrobacter citreus ${ }^{4}$ was remarkably affected by trace elements in medium. One of the most important factors was manganese. Effect of manganese on IMP production by KY 3446 was therefore examined. Figure 3 shows that excessive addition of $\mathrm{Mn}^{2+}$ stimulated growth and suppressed IMP accumulation to a marked degree as in the cases of two organisms reported previously. ${ }^{4}$

7) J. G. Buchanan, C. A. Dekker and A. G. Long, J. Ghem. Scc., 1950, 3162 . 


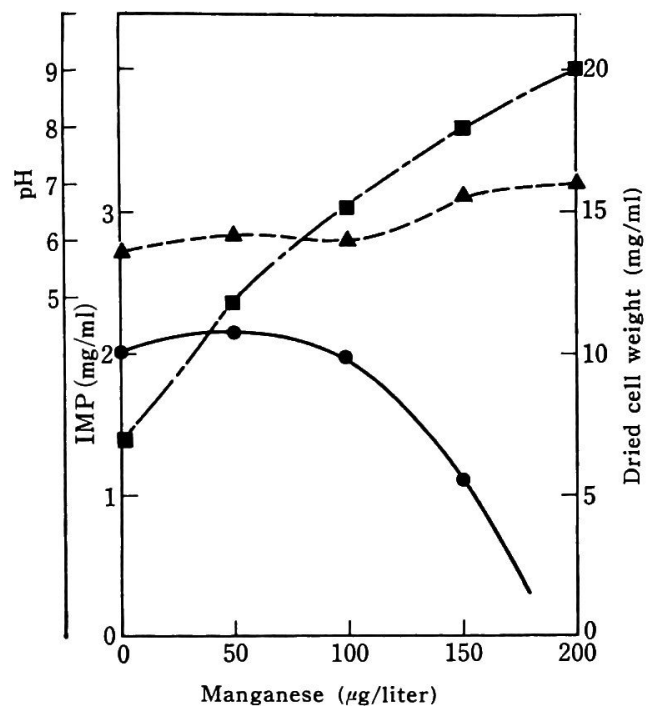

FIG. 3. Effect of Manganese on Growth and IMP Production.

Basal medium; glucose $10 \%, \mathrm{~K}_{2} \mathrm{HPO}_{4} 1 \%$, $\mathrm{KH}_{2} \mathrm{PO}_{4} 1 \%$, yeast extract $1 \%, \mathrm{MgSO}_{4} \cdot 7 \mathrm{H}_{2} \mathrm{O} 1 \%$, $\mathrm{CaCl}_{2} \cdot 2 \mathrm{H}_{2} \mathrm{O} 0.01 \%$, urea $0.6 \%$ biotin $30 \mu \mathrm{g} /$ liter $\mathrm{pH}$ was adjusted to 8.2 with $5 \mathrm{~N}-\mathrm{NaOH}$. Hypoxanthine $0.3 \%$ was added 3 days after inoculation. Analyses were made for 5 day culture broth.

$$
\begin{array}{ll}
-1 & \text { IMP produced } \\
-\square- & \text { Growth } \\
-\Delta- & \mathrm{pH}
\end{array}
$$

Microscopic observation further showed that the bacterial cells grown at the optimal concentration of $\mathrm{Mn}^{2+}$ for IMP production were large and swelled form (Fig. 4), whereas those grown with excessive $\mathrm{Mn}^{2+}$ (inhibitory to IMP production) were small and normal form (Fig. 5). It is hence clear that the concentration of $\mathrm{Mn}^{2+}$ in medium definitely caused morphogenetic alteration of $\mathrm{Br}$. insectiphilium, and that the changes might be closely related with extracellular nucleotide production.

During examination on effect of manganese, it was noted that culture broth with excessive $\mathrm{Mn}^{2+}$, when acidified with $\mathrm{HCl}$, became red color; and the higher the manganese level in medium, the deeper the red color of broth was. It was thus speculated that more manganese

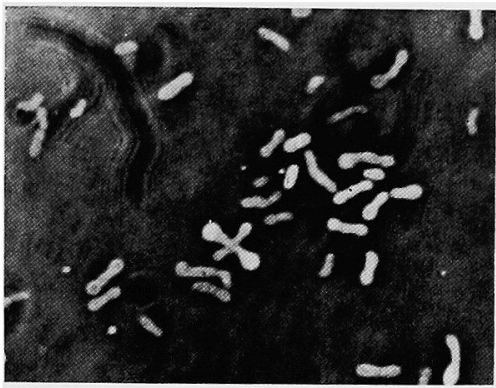

FIG. 4. Cells Grown at the Optimal Concentration of $\mathrm{Mn}^{2} r$ for IMP Production.

Medium; glucose $10 \% ; \mathrm{K}_{2} \mathrm{HPO}_{4} 1 \%, \mathrm{KH}_{2} \mathrm{PO}_{4}$ $1 \%$, yeast extract $1 \%, \mathrm{MgSO}_{4} \cdot 7 \mathrm{H}_{2} \mathrm{O} 1 \%, \mathrm{CaCl}_{2}$. $2 \mathrm{H}_{2} \mathrm{O} 0.01 \%$, urea, $0.6 \%$, biotin $30 \mu \mathrm{g} /$ liter and hypoxantine $0.3 \%$ (added 3 days after inoculation). $\mathrm{pH}$ was adjusted to 8.2 with $5 \mathrm{~N}-\mathrm{NaOH}$ before autoclaving. Incubation was carried out for 5 days.

Dried cell weight: $7.9 \mathrm{mg} / \mathrm{ml}, \mathrm{pH}: 6.4$, IMP produced: $2.15 \mathrm{mg} / \mathrm{ml}$.

Magnification $\times 2000$.

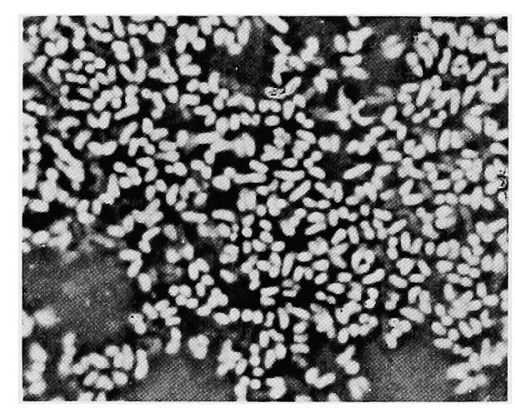

FIG. 5. Cells Grown at the Excessive and Inhibitory Concentration of $\mathrm{Mn}^{2+}$ to IMP Production.

Medium; the same as in Fig. 4 except $\mathrm{Mn}^{2+}$ (200 $\mu \mathrm{g} /$ liter).

Dried cell weight: $20.9 \mathrm{mg} / \mathrm{ml}, \mathrm{pH}: 7.2$, IMP not produced.

Magnification $\times 2000$.

concentration in medium might cause the formation of an unknown red pigment. The indentification of the pigment has not yet been carried out.

\section{Effect of zinc on IMP production}

Figure 6 shows that excessive addition of zinc markedly inhibited IMP production, but the inhibitory concentration of zinc to IMP 


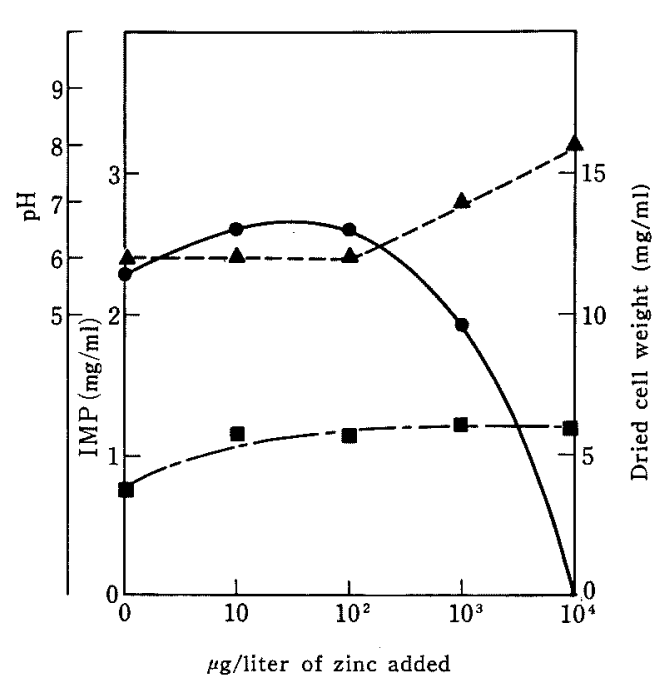

FIG. 6. Effect of Zinc on Growth and IMP Production.

Basal medium; the same as in Fig. 3. Hypoxanthine $0.3 \%$ as final concentration was added 3 days after inoculation. Incubation was carried out 5 days.

$$
\begin{array}{ll}
-1 & \text { IMP produced } \\
-\square- & \text { Growth } \\
- & \text { pH }
\end{array}
$$

formation was extremely higher than that of manganese.

Nitrogen source

Effects of inorganic nitrogen salts on IMP production are shown in Table II. Both am-

TABLE II. EFFECT OF INORGANIC NitRogenous Compounds on IMP PRODUCTION

$\begin{array}{lcccc}\begin{array}{l}\text { Inorganic nitrogen } \\ \text { compounds added } \\ (\% 6)\end{array} & \text { pH } & \begin{array}{c}\text { Dried cell } \\ \text { weight } \\ (\mathrm{mg} / \mathrm{ml})\end{array} & \begin{array}{c}\text { IMP produced } \\ (\mathrm{mg} / \mathrm{ml})\end{array} \\ \mathrm{NH}_{4} \mathrm{Cl} & 1.0 & 7.8 & 16.8 & 1.17 \\ \left(\mathrm{NH}_{4}\right)_{2} \mathrm{SO}_{4} & 1.0 & 7.8 & 15.1 & 1.33 \\ \text { Urea } & 0.6 & 6.2 & 6.9 & 2.32\end{array}$

Basal medium; glucose $10 \%, \mathrm{~K}_{2} \mathrm{HPO}_{4} 1 \%, \mathrm{KH}_{2} \mathrm{PO}_{4}$ $1 \%$, yeast extract $1 \%, \mathrm{MgSO}_{4} \cdot 7 \mathrm{H}_{2} \mathrm{O} 1 \%$, biotin $30 \mu \mathrm{g} /$ liter and $\mathrm{CaCO}_{3} 3 \%$ : In the case of urea, $\mathrm{CaCl}_{2} \cdot 2 \mathrm{H}_{2} \mathrm{O} \quad 0.01 \%$ was added instead of $\mathrm{CaCO}_{3}$. The mixture was adjusted to $\mathrm{pH} 8.2$ with $5 \mathrm{~N}-\mathrm{NaOH}$ before autoclaving. Hypoxanthine $0.3 \%$ was added 3 days after inoculation. Analyses were performed for 5 day culture broth. monium chloride and ammonium sulfate gave growth yields twice as much as urea, but formed IMP only a half as much as urea. Hence urea has been used exclusively throughout the other experiments.

\section{Carbon source}

It was then examined if various carbon sources except glucose were available for IMP production by KY 3446. Carbon sources tested were fructose, mannose, galactose, xylose, sucrose, maltose, sorbit, mannit and starch, and their concentrations were 5 and $10 \%$.

The strain was able to grow in the medium containing maltose, sucrose or starch, but failed to grow on other carbon sources.

It is of particular interest that KY 3446 could grow on sucrose and markedly accumulated IMP from sucrose. This finding is in contrast with $M$. sodonensis and $A$. citreus that were unable to grow and produce IMP on sucrase as a sole carbon source.

The sucrose medium also yielded IMP from hypoxanthine or adenine and UMP from uracil or cytosine, respectively (Table III). The quantities of IMP and UMP produced from sucrose were somewhat larger than those from glucose.

The chemical changes in typical fermentation are given in Fig. 7.

TABLE III. IMP AND UMP PRODUCTION ON SUCROSE MEDIUM

$\begin{array}{lccc}\text { Bases added } & \mathrm{pH} & \begin{array}{c}\text { Dried cell } \\ \text { weight } \\ (\mathrm{mg} / \mathrm{ml})\end{array} & \begin{array}{c}\text { Accumulated } \\ \text { product } \\ (\mathrm{mg} / \mathrm{ml})\end{array} \\ \text { Adenine } & 6.8 & 15.4 & \text { IMP } 2.97 ; \\ \text { Hypoxanthine } & 6.0 & 9.9 & \text { IMP } 3.17 \\ \text { Cytosine } & 6.0 & 9.0 & \text { UMP } 1.52 ; \text { uracil } \\ \text { Uracil } & 6.4 & 12.0 & \text { UMP } 1.87\end{array}$

Medium; sucrose $10 \%, \mathrm{~K}_{2} \mathrm{HPO}_{4} 1 \%, \mathrm{KH}_{2} \mathrm{PO}_{4} 1 \%$, yeast extract $1 \%, \mathrm{MgSO}_{4} \cdot 7 \mathrm{H}_{2} \mathrm{O} 1 \%, \mathrm{CaCl}_{2} \cdot 2 \mathrm{H}_{2} \mathrm{O}$ $0.01 \%$, urea (autoclaving separately) $0.6 \%$ biotin $30 \mu \mathrm{g} /$ liter. The mixture was adjusted to $\mathrm{pH} 8.3$ before autoclaving. Each base $0.3 \%$ was added 3 days after inoculation. Analyses were made for 5 day culture. 


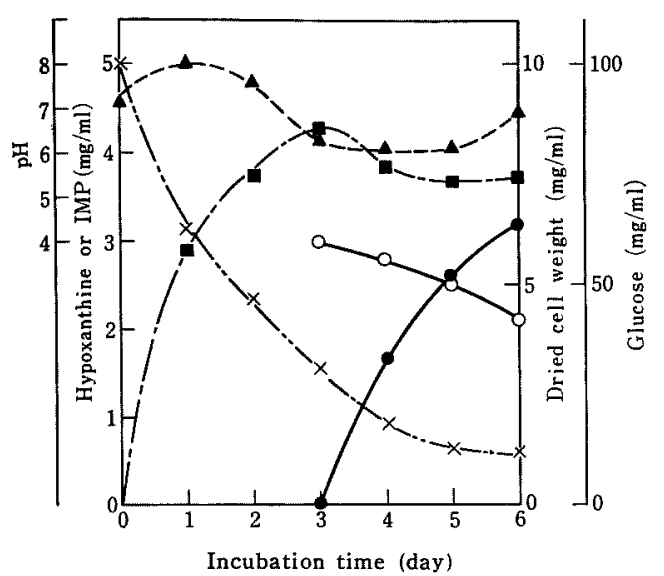

Fig. 7. Chemical Changes in IMP Fermentation.

Medium; glucose $10 \%, \mathrm{~K}_{2} \mathrm{HPO}_{4} 1 \%$, yeast extract $1 \%, \mathrm{MgSO}_{4} \cdot 7 \mathrm{H}_{2} \mathrm{O} 1 \%, \mathrm{CaCl}_{2} \cdot 2 \mathrm{H}_{2} \mathrm{O} 0.01 \%$, urea $0.6 \%$, biotin $30 \mu \mathrm{g} / \mathrm{liter}$. The mixture was adjusted to $\mathrm{pH} 8.2$ before autoclaving. Hypoxanthine $0.3 \%$ was added 3 days after inoculation.

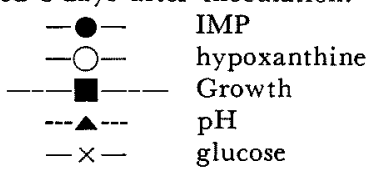

\section{DISCUSSION}

Although enzymatic studies have not been made, a stoichiometric match between quantities of hypoxanthine decrease and those of IMP formation in the chemical changes (Fig. 7) suggests that $\mathrm{Br}$. insectiphilium appears to produce IMP and UMP from bases corresponding. to those by salvage pathway via PRPP (probably by IMP or UMP pyrophosphorylase) as in the case of $M$. sodonensis and Arth. citreus."
It is noteworthy, in contrast with $M$ : sodonensis and Arth. citreus, that Br. insectiphilium produced IMP from adenine and UMP from cytosine. The formation of hypoxanthine in the culture broth to which adenine was added and that of uracil in the culture broth to which cytosine added might suggest that adenine and cytosine added were subject to deamination, and IMP or UMP was then accumulated from hypoxanthine or uracil produced, respectively.

As for IMP production from inosine, it may be proper to consider that the pathway would be: inosine $\rightarrow$ hypoxanthine $\rightarrow$ IMP, because fermentation to which inosine was added yielded hypoxanthine. The above consideration could be applied analogously to the case of adenosine addition: that is, adenosine added as a precursor was deaminated at the level of nucleoside or base, and IMP was then accumulated through the same pathway as inosine or adenine. Apart from the probable pathway (depicted in Fig. 8), it is of particular interest that adenine and adenosine were available for IMP accumulation as precursors and cytosine for UMP accumulation.

The bacterial cells grown at the optimal concentration of $\mathrm{Mn}^{2+}$ for IMP accumulation were large and swelled form, whereas cells grown at the excessive and inhibitory concentration of $\mathrm{Mn}^{2+}$ for IMP accumulation showed small and normal form. These facts suggest that morphogenetic alteration might be closely related to nucleotide accumulation. On the basis of these findings, it seems reason-

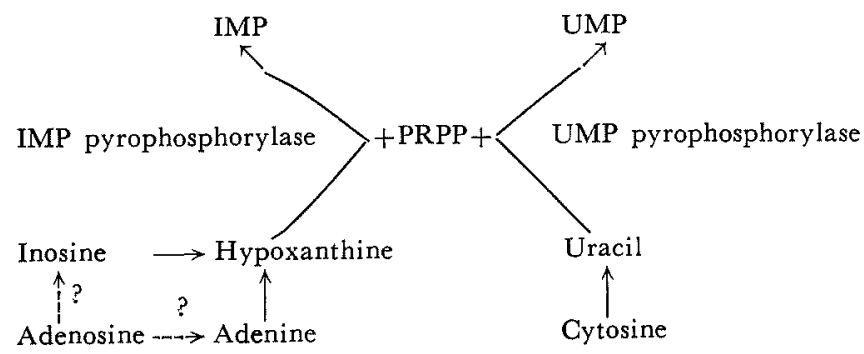

FIG. 8. Probable Pathway for IMP and UMP Formation by Br. insectiphilium. 
able to presume that the deficiency of $\mathrm{Mn}^{2+}$ permeability might increase in this stage of for bacterial growth induces morphogenetic cells. Analogous speculation has been made alteration from normal small to abnormal in connection with leakage of salvage enzymes large cells suitable for IMP accumulation: outside of cells in IMP production by $M$. that is, "cell lysis" In other words cell sodonensis." 